\title{
Desde el paradigma cualitativo: inflexiones en un metarrelato
}

\author{
Jorge Luis Barboza ${ }^{1}$
}

\section{Introducción}

Hablar de tradición cualitativa tiene un doble sentido, una doble vía. Primero, significa que después de múltiples polémicas, el paradigma crítico reflexivo se ha consolidado sobre la base de argumentos epistemológicos y empíricos sólidos. Segundo, que comienza un camino de anquilosamiento, aparición de recetarios que serían el propio espejo de lo criticado al positivismo. Ya existen atisbos, síntomas de ese proceso en la elaboración de trabajos de grado y/o tesis.

Este posible estancamiento de las investigaciones cualitativas, en ocasiones obedece a la buena intención de mantener un estándar de rigurosidad científica, rigurosidad que se confunde con el endurecimiento en la forma, el recorrido y estructuración del informe final, en oposición a la flexibilidad que toda investigación dentro de este paradigma posee de suyo. En nuestra opinión, una de sus mayores fortalezas es la posibilidad que brinda para echar mano de distintos métodos producto de la necesidad misma de la investigación, cuando esta nos exige la revisión de formas alternativas para poder descubrir y describir el fenómeno estudiado. Es el río de Heráclito, o mejor en el de Cratilo (Aristóteles, IV, p. 191): no podremos bañarnos en el mismo río "ni siquiera una vez".

Es necesario dejar que las investigaciones respiren por sí mismas, sin camisas de fuerza, en diálogo constante con el objeto de estudio, con los sujetos y con su contexto, es así como podremos acercarnos al inalcanzable horizonte de la verdad, a los horizontes de sucesos. A través de la dialogicidad podemos cohabitar con

$1 \quad$ Doctor en Educación. MSc. en Docencia para la Educación Superior. Licenciado en Letras. Docente Investigador de la Corporación Universitaria del Caribe. Editor. Correos: jorge.barbozah@cecar.edu.co; jorgelbarbozah@gmail.com 
distintas perspectivas, incluso, opuestas, esta dialéctica exige seres con mentalidad no solo científica, sino también amplia, creativa y creadora.

En ese proceso dialéctico de la investigación, conflictuándonos, escuchándola, cuestionándola, negociando, transándonos, realizamos el estudio del fenómeno de la lectura en estudiantes universitarios y maestros del subsistema primaria. En el primer caso, en los estudios de maestría, aprendimos del fenómeno, del paradigma y del método investigación-acción en el aula.

Esta investigación se inició antes de comenzar la maestría y continuó luego de culminada. De ella emergió una teoría sustantiva y una colección de libros para estimular el desarrollo de la compresión a través de la lectura dirigida a niños y maestros de ler. a 6to. grado.

Ese trabajo posterior a la tesis de maestría dio pie a nuevas interrogantes que tomamos para desarrollar la tesis doctoral, en la cual surgieron nuevos problemas y necesidades a las que debimos dar respuesta situacionalmente. Las relaciones inmanentes entre objeto de estudio, sujetos de la investigación y el contexto nos obligó a recurrir a métodos y metodologías alternativas al visualizado inicialmente para realizar el recorrido investigativo; la investigaciónacción. En otras palabras, fueron las demandas del estudio las que nos indicaban nuestros vacíos y exigían con qué método debíamos abordar un momento equis de la investigación. Esta flexibilidad es la que considero debemos promover porque constituye un constante refrescamiento del paradigma cualitativo y evitaría la canonización in extremis de sus métodos.

De manera que en el relato que presentaremos a continuación tiene como propósito describir, lógicamente de forma aproximada, el tránsito de la investigación con las reflexiones sobre el objeto de estudio, la lectura, y expondremos los hallazgos a través de las evidencias, de esta forma esperamos que sirva a los no iniciados como ejemplo del no-modelo, de la imposibilidad de presentar un modelo estándar para los estudios enmarcados en el paradigma crítico-reflexivo, pero a que su vez sirva como un texto generador de ideas y alternativas en estudios de naturaleza empírica como estos. 
Por último, debemos aclarar que nuestra intención no es presentar un modelo de informe final para obtener un grado, $\mathrm{y}$ tampoco de artículo científico, es sencillamente una especie de ensayo, metarrelato, muy cercano a la sistematización de experiencias que intenta explicar el conjunto de vicisitudes, vaivenes, pequeños fracasos y éxitos que se presentan en toda investigación. Es inevitable la asincronía entre los acontecimientos y la narración, así que muchas veces no podremos explicar las historias y hechos que en la realidad estuvieron superpuestos.

\section{Génesis y evolución de las ideas}

En los años 90, siendo docente en secundaria, una de mis mayores preocupaciones fue la deficiencia de mis estudiantes en la comprensión de textos. Luego de algunos intentos por resolver el problema y dados los resultados alcanzados, muy deficientes, concluí que hacían falta nuevas herramientas porque girábamos en círculos; no existían avances significativos que se correspondieran con los esfuerzos realizados.

Para esa misma época tuvimos acceso a la teoría constructivista aplicada a la educación, la cual aportó valiosas explicaciones, sobre todo las realizadas por Ferreiro y Teberosky (1991) en cuanto al proceso de adquisición de la lengua escrita.

Al final de la misma década, los aportes de Sánchez (1996, 1997, 2000), atinentes al desarrollo de las habilidades del pensamiento fueron fundamentales en la conformación de un conjunto de estrategias que sirvieron de guía para abordar el problema, aunque no de manera definitiva porque su perspectiva cognitiva-conductual deja de lado los aspectos afectivo y contextual de los lectores. Intermitentemente vuelvo sobre la lectura y paulatinamente comienza a avizorarse una metodología consistente.

Luego de transitar por diversas experimentaciones intuitivas en lo cognitivo y académico, al cursar los estudios de Maestría, específicamente la Maestría en Docencia para la Educación Superior de la Universidad Nacional Experimental "Rafael María Baralt" (UNERMB) realicé la investigación Estrategias interactivas grupales 
para consolidar la comprensión lectora (Barboza, 2009), enmarcada en el paradigma crítico reflexivo, método investigación-acción en el aula, aplicada a estudiantes de Educación Integral de la mencionada universidad.

Esta experiencia produjo, por un lado, un conjunto de estrategias constructivistas que estimulan el desarrollo de la lectura en el aula, replicables en cualquier nivel del sistema educativo con la debida adecuación de los textos al nivel de desarrollo cognitivo de los estudiantes. Dichas estrategias han sido aplicadas en primaria y educación media con éxito. Por el otro, una teoría sustantiva para la "comprensión lectora" en el aula, teoría que se ha venido desarrollando y ampliando, a la cual en aquel momento denominé Holopraxis de la lectura en el aula.

\section{Construcción de los propósitos de la investigación}

Para consolidar los hallazgos previos que ratificaban la situación atrás descrita, en la tesis doctoral planificamos la investigación en tres momentos prácticos. En el primero, develé la concepción que tienen los docentes de la lectura como proceso didáctico. En el segundo momento, ejecutamos la acción central, consistente en lograr la transformación del concepto de lectura como proceso didáctico en el hacer, para ello facilité a las docentes participantes talleres de estrategias de lectura con el fin de incorporarlas durante un periodo de un año escolar, aproximadamente, en sus prácticas de las docentes, brindándoles acompañamiento en ese recorrido. Por último, una vez culminada la aplicación de las estrategias, volví a indagar el concepto de lectura como proceso didáctico.

Sin embargo, estos propósitos de la investigación fueron evolucionando con la investigación misma. Paulatinamente fueron emergiendo ideas e información que nos hacían reorientar su rumbo. Sin duda, teníamos definido el objeto de estudio, pero cómo debíamos indagar e, incluso, qué debíamos indagar exactamente, no estaba totalmente claro.

Por ejemplo, las docentes exponían que los niños comprendían poco o "nada" de lo leído y algunos escribían, pero no leían, que tenían 
lectura silábica, etc. En otras palabras, mezclaban dos concepciones distintas y contrapuestas. Esta fue la razón por la cual me pregunté ¿Qué concepto de lectura que tienen los docentes? De allí surgió el primer propósito:

- Develar el concepto de lectura como proceso didáctico en docentes y su transposición didáctica.

Debemos decir, además, que su redacción fue evolucionando. En un primer momento fue "Indagar el concepto de lectura en docentes y su transposición didáctica". Más tarde sustituimos indagar por develar y un punto importante fue la inclusión establecer que era "como proceso didáctico" porque comprendimos, gracias a la etnometodología, que podían tener una concepción de la lectura en el rol de profesionales de la docencia y otro en el rol de padres y madres, por ejemplo.

Nuestra intención era profundizar al máximo en la problemática de la lectura, nos preguntamos dónde y cómo se originaba el concepto de lectura develado, por eso nos propusimos:

- Descifrar el origen del concepto de lectura como proceso didáctico develado.

Empíricamente, sabíamos que la problemática de la lectura en las aulas era (y es) profunda, por lo que intuíamos cuál era el concepto que sobre la lectura tenía el docente, sin embargo, debíamos precisarlo. Luego, estimamos que por nuestra propia naturaleza pragmática y con el fin de romper con el círculo vicioso de la lectura, debíamos trabajar con los docentes a fin de provocar una transformación en su praxis. De allí, los siguientes dos propósitos:

- Propiciar la transformación del concepto de lectura como proceso didáctico en docentes.

- Promover cambios en la didáctica de la lectura en docentes.

Además, también teníamos una inquietud personal: habíamos generado una teoría sustantiva con resultados prácticos positivos a nivel universitario y en primaria, pero hacía falta el estudio científico que explicara y respaldara su efectividad. Sin embargo, para las investigaciones cualitativas es de suma dificultad hacer 
generalizaciones por su naturaleza epistemológica, esto constituía un reto. Una forma de generalizar es replicar la experiencia en distintos escenarios y momentos, dado el número de participantes se nos presentaba una oportunidad única de validar la teoría sustantiva denominada Holopraxis de la lectura. En consecuencia nos plateamos:

- Validar, vía replicación de la experiencia, la metodología sobre el desarrollo de la comprensión de textos propuesta por el autor (Holopraxis de la lectura) en los subsistemas Primaria y Secundaria.

Todas las fases de la investigación se desarrollaron en el municipio Cabimas, estado Zulia, Venezuela. En el primer y segundo propósito estuvieron involucradas 5 (cinco) instituciones educativas, una de secundaria y 4 (cuatro) de primaria (2 públicas y 2 privadas). Para el resto de los propósitos participaron tres instituciones públicas, una de secundaria y dos de primaria. En cuanto al periodo, comenzó en octubre de 2012 y finalizó en el mes de mayo de 2016.

\section{Los sujetos de la investigación}

Para el momento de iniciar el estudio éramos docente en la maestría Administración de la Educación Básica del postgrado de la UNERMB. En esas circunstancias un grupo de participantes se me acercaron para solicitar mi asesoría en su Trabajo de Grado. Luego de varias conversaciones decidimos formar un colectivo de investigación cuyo objeto de estudio sería la lectura en el aula.

Por la misma inquietud que las embargaba, el método de trabajo fue la investigación-acción, de forma que sus sujetos de estudio serían sus propios alumnos. En cuanto a mí, ellas fueron mis sujetos de estudio y co-investigadoras.

$$
\text { Investigador } \rightarrow \begin{gathered}
\text { Sujetos } \\
\text { de } \\
\text { estudio }
\end{gathered} \rightarrow \underset{\text { Maestras co- }}{\text { investigadoras }} \rightarrow \rightarrow \begin{gathered}
\text { Sujetos } \\
\text { de } \\
\text { estudio }
\end{gathered} \rightarrow \text { Alumnos }
$$

Figura 1. Sujetos de estudio.

Para este momento pensaba que al ocurrir la transformación en las maestras, ocurría la transformación en los alumnos. 


\section{Métodos}

La formación del investigador siempre es inacabada, un horizonte en constante transformaciones. Cada estudio implica nuevos retos, perspectivas, elaboraciones y reelaboraciones teóricas, metódicas y metodológicas, podríamos decir que no hay tiempo para aburrirse.

Podemos repetir el método y la metodología, sin embargo, siempre habrá particularidades propias del contexto social y del objeto de estudio. A continuación, exponemos el recorrido metódico de la investigación.

\section{Etnometodología}

Las interacciones son parte del mundo de vida individual y colectivo, "un mundo de rutinas en el que los actos de la vida cotidiana son realizados, en su mayoría, maquinalmente." (Coulon, 1988:14). Y si bien es cierto que el fin último de la investigación acción es la transformación del Ser y de la sociedad, también es cierto que debemos tener herramientas coherentes con el método para evidenciarla e interpretar esta transformación.

En la explicación de Garfinkel (2006, p. IX) sobre el origen del término etnometodología afirma:

Por etno quería expresar, de alguna u otra manera, que los miembros de una sociedad tienen disponibles para su uso ciertos conocimientos que son del sentido común de esa sociedad, conocimientos sobre «cualquier cosa».

Para develar el concepto de lectura como proceso didáctico en las docentes y su transposición didáctica nos vimos en la necesidad introducirnos en el modo de pensar de las docentes, fueron numerosos encuentros en talleres y conversaciones personales que paulatinamente me permitió comprender qué sucedía en sus mentes. Gracias a la etnometodología pudimos develar la relación pensamiento-acción.

Esta interacción nos permitió descubrir que había una disonancia entre lo que planteaban en cuanto a la problemática de la 
lectura en aula, los conceptos que expresan sobre el objeto mismo y su praxis en el aula.

Para explicarnos mejor recurriremos al Cuadro 1:

\begin{tabular}{|c|c|}
\hline $\begin{array}{c}\text { Paradigma del silabario } \\
\text { (sintético) }\end{array}$ & $\begin{array}{c}\text { Paradigma constructivista } \\
\text { (analítico) }\end{array}$ \\
\hline $\begin{array}{c}\text { Desconoce el desarrollo cognitivo } \\
\text { del niño }\end{array}$ & $\begin{array}{c}\text { Respeta del desarrollo cognitivo } \\
\text { del niño }\end{array}$ \\
\hline $\begin{array}{c}\text { Va de las partes al todo } \\
\text { letras } \rightarrow \text { sílabas } \rightarrow \text { palabras } \rightarrow \\
\text { frases, oraciones) }\end{array}$ & $\begin{array}{c}\text { Aprendemos a leer de lo general a } \\
\text { lo particular (del todo a las partes) } \\
\text { (oraciones, frases } \rightarrow \text { palabras } \rightarrow \\
\text { sílabas } \rightarrow \text { letras) }\end{array}$ \\
\hline $\begin{array}{c}\text { Hace hincapié en lo fonético } \\
\text { (Leer es decodificar) }\end{array}$ & $\begin{array}{c}\text { Hace hincapié en la comprensión } \\
\text { (Leer es construir significados) }\end{array}$ \\
\hline Utiliza textos descontextualizados & Lectura contextualizada \\
\hline $\begin{array}{c}\text { Primero se aprende a leer y luego a } \\
\text { escribir }\end{array}$ & $\begin{array}{c}\text { Se aprende a leer y escribir } \\
\text { simultáneamente }\end{array}$ \\
\hline $\begin{array}{c}\text { Aprender a leer es un acto } \\
\text { individual }\end{array}$ & Leer es un acto individual y social \\
\hline La comprensión viene después... & Leer es comprender \\
\hline Escribir es transcribir & Escribir es producir significados \\
\hline
\end{tabular}

Cuadro 1. Paradigma del silabario vs. Paradigma constructivista.

Fuente: Elaboración propia.

En el cuadro anterior están claramente establecidas y contrastadas las características del paradigma del silabario y del paradigma constructivista. El primero, aunque su origen es anterior al conductismo, se encuadra perfectamente en este modo de pensar y actuar.

Por mi formación constructivista creía que todas las docentes concebían la lectura desde esta perspectiva y me apoyaba en el hecho de que la educación primaria venezolana desde los años 90 había asumido este conjunto de teorías en los currículos. En los talleres que facilitaba sobre el tema, mi intención era reforzar esta concepción, aclarar el propósito de las prácticas y profundizar en ellas. Pero en las intervenciones de las participantes, comencé a notar una discordancia entre lo que decían de "el deber ser" de la lectura y los realmente hacían en el aula. Un algún momento pensé que trataban 
de complacer al facilitador, es decir, expresaban lo que el facilitador quería oír (posiblemente en algunas ocasiones fue así), pero en las conversaciones espontáneas, ya relajadas, afloraban la verdadera concepción y prácticas sobre la lectura como proceso didáctico.

Desde el punto de vista epistemológico, en algún momento pensamos que estaba en el campo de la fenomenología, pues según Taylor y Bogdan (1992), su fin es descubrir en el fenómeno su esencia válida y útil, de allí que el investigador -fenomenólogo- debe aprender a ver las cosas desde el punto de vista de otras personas para llevar a la práctica esa epojé, o ubicar entre paréntesis la realidad, es decir, suspender los juicios, creencias y teorías acerca de la misma.

La fenomenología, por lo tanto, no se ocupa de los hechos, sino que se enfoca en lo esencial, lo necesario, lo a priori, para lo cual debe suspender o colocar entre paréntesis todas las experiencias relativas al mundo natural, las proposiciones de las ciencias, las creencias, el estrato mundano-trascendental, para prescindir o dejar fuera de consideración todo lo accidental, fáctico y contingente en el objeto.

En cambio, mi propósito era trascender la hermenéutica, la comprensión, e ir a lo factual porque debía contrastar lo conceptual en las maestras con sus haceres en el aula, esto me llevó a la etnometodología, porque ella proporciona la epistemología desde la cual podemos explicar la construcción social de la realidad y el método para abordar y comprender cómo estructuran los sujetos la cotidianidad, en este caso, en la lectura como proceso didáctico en la escuela.

Para Coulon (1988), "La etnometodología es la búsqueda empírica de los métodos empleados por los individuos para dar sentido y, al mismo tiempo, realizar sus acciones de todos los días: comunicarse, tomar decisiones, razonar" (p.32).

En la explicación de Garfinkel (2006), sobre el origen del término etnometodología afirma: Por etno quería expresar, de alguna u otra manera, que los miembros de una sociedad tienen disponibles para su uso ciertos conocimientos que son del sentido común de esa sociedad, conocimientos sobre «cualquier cosa»" (p. IX). 
La etnometodología estudia las actividades que los miembros de un grupo producen y por medio de las cuales controlan los escenarios de hechos cotidianos, tácitamente hay acuerdos, un sentido común, que permiten la comunicación y actuación coherente entre ellos, esto es observable y explicable, es decir, se puede dar cuenta de ellos. De esta manera, la etnometodología me daba luces para realizar la conexión entre los pensamientos de las maestras y sus actos, podía comprender y explicar la semiología de las acciones; cómo concebían las maestras la lectura y cómo ejecutaban sus prácticas de lectura en el aula.

En conclusión, en las maestras convivían dos concepciones opuestas, por un lado, sus prácticas eran conductistas, concebían tácitamente la lectura dentro del paradigma del silabario, pero por el otro lado querían alcanzar objetivos propios del paradigma constructivista. Esto no era posible porque en su formación no había conocimiento y haceres suficientes que le permitieran comprender la diferencia entre ambas perspectivas.

\section{Investigación-Acción (IA)}

Cuando hacemos investigación cualitativa, la realidad nos exige qué caminos recorrer y con qué recorrerlos. Las co-investigadores y yo nos propusimos la transformación de una realidad. Ellas, encontrar la forma para que sus alumnos desarrollaran la comprensión de la lectura. Yo, que ellas transformaran su concepto sobre la lectura como proceso didáctico.

Aunque no existe unanimidad en su definición, para algunos autores la IA se centra en la resolución de problemas ligados a contextos sociales y a investigadores comprometidos con el cambio social. Para otros, es concebida como un cambio de paradigma que encierra una concepción política de la ciencia. En todo caso, la investigación pierde su estatus elitista de pertenecer a la clase privilegiada de los investigadores, porque ella ofrece una experiencia de aprendizaje colaborativo donde se diluyen las distancias entre los investigadores y los investigados, consecuentemente se conforma una comunidad o colectivo de reflexión con miras a evaluar y resolver conflictos. 
Carr y Kemmis (1988, p. 174) la definen como una "indagación autorreflexiva" de los participantes en contextos sociales con el propósito de mejorar la lógica, la comprensión y la justicia de sus propias acciones y situaciones dentro de las cuales ellas tienen lugar.

Aplicada a la práctica educativa, la finalidad básica de la IA no es, esencialmente, la acumulación de conocimientos sobre la enseñanza o la comprensión de la realidad educativa, sino, fundamentalmente, aportar información para guiar la toma de decisiones y los procesos de cambio. Es decir, su objetivo es optimizar la práctica educativa, más que generar conocimientos, aunque en ningún momento los conocimientos producidos son dejados de lado (Elliott, 1994).

En consideración a las ideas expuestas por Carr y Kemmis (1988), conformamos un colectivo integrado por docentes de los niveles de educación primaria que, además, eran participantes de la maestría en Administración de la Educación Básica. Como ya dijimos, el estudio de la lectura se realizó en dos niveles. El primer nivel es el de los docentes de Educación Básica, quienes investigaron en sus aulas, con sus alumnos el fenómeno de la lectura y la transformación de los participantes.

Como ya expliqué, en la didáctica de la lectura de las maestras subyacían conocimientos tácitos que no permitían una pedagogía adecuada de la lectura. Cuando se confrontaron con la problemática y la incapacidad de resolverla, comenzaron a explicitarse sus falencias y necesidades, así los conocimientos didácticos tenidos hasta ese momento fueron conscientemente insuficientes y/o quedaron obsoletos. Los nuevos conocimientos alcanzados gracias a la interacción constante entre la teoría y la práctica con sus estudiantes, consolidaron una nueva conciencia de su rol docente. Fue en ese momento cuando emergió la transformación.

Por otro lado Lyotard (1991) plantea:

...se enseña lo que se sabe: así es el experto. Pero, a medida que el estudiante (el destinatario de la didáctica) mejora su competencia, el experto puede hacerle partícipe de lo que no sabe y trata de saber (si el experto es, además, investigador). El estudiante es introducido 
así en la dialéctica de los investigadores, es decir, en el juego de la formación del saber científico (p. 23).

Elliott (1994) afirma que queda poco espacio para "la idea de la enseñanza como reflexión-en-la-acción" (p. 96). Las universidades forman educadores reproductores, no educadores capaces de reflexionar sobre su praxis; vale decir que, en general, los docentes universitarios tampoco reflexionan sobre su quehacer, en consecuencia, es imposible formar docentes investigadores-creadores de su entorno social. El desarrollo profesional del docente se limita si sólo se dispone de la experiencia propia para reflexionar sobre los problemas del aula, en vez de compartir las diversas perspectivas acerca de los problemas comunes a todos con otros. De allí la necesidad de emprender investigaciones cooperativas y compartir los hallazgos.

Es clave la formación del docente investigador que indague su entorno y genere sus propios conocimientos en vez de aplicar únicamente los conocimientos de otro. No es casual que se afirme de la epistemología positivista que "este tipo de investigación siempre mostrará la tendencia a favorecer las disposiciones educativas preexistentes, y sus teorías se estructurarán a favor del statu quo." (Carr \& Kemmis, 1988, p. 94). La investigación-acción promueve la autoformación del ser en el hacer.

La estructura y estructuración del pensamiento positivistaconductista también favorece su reproducción y permanencia acrítica en todas las áreas del conocimiento, es aceptado como verdad única e indiscutible. Este pensamiento incide en la concepción de la lectura, por ello es crucial "el uso de una metodología que le permita describir [al investigador] cómo interpretan los individuos sus actos y las situaciones dentro de las cuales actúan" (Carr \& Kemmis, 1988, p. 94).

Con miras a mejorar la práctica educativa, promovimos la reflexión a fin de deconstruir el pensamiento conductista, las coinvestigadoras desentrañaron el fondo y trasfondo de sus prácticas en el aula. Las interpretaciones de las coinvestigadoras fueron objeto de un ejercicio hermenéutico que aportó insumos para comprender 
lo ocurrido durante la investigación y hacer inteligible las acciones de las docentes.

Las acciones siempre incorporan las interpretaciones del actor y por ese motivo sólo pueden ser entendidas cuando nos hacemos cargo de los significados que el actor les asigna. Una de las misiones de la ciencia social «interpretativa» consiste en descubrir esos significados y, así, hacer inteligible la acción. (Carr \& Kemmis, 1988, p. 103).

Recordemos que buscábamos, partiendo de una línea base, develar el concepto de lectura como proceso didáctico, su transformación luego de una serie de acciones emprendidas en conjunto y su incidencia en la praxis del aula. Para ello hubo dos variantes de la investigación-acción. La primera, investigación-acción en el aula, y la segunda, colaborativa.

El trabajo desarrollado por las docentes en el aula con sus alumnos constituyó IA en el aula. Ellas se plantearon propósitos y ejecutaron acciones en busca de cambios en sus alumnos. Por mi parte, observé los cambios ocurridos en ellas.

Toda IA es colaborativa; sin embargo, en este caso no hubo de mi parte trabajo en el aula como docente, fui el tutor de ese grupo de participantes de la Maestría en Administración de la Educación Básica; se conformó un equipo de trabajo colaborativo a fin de conseguir los propósitos propuestos en cada uno de los casos. Elliott (1994), comenta sobre la IA:

Se trata de una actividad emprendida por grupos o comunidades con el objetivo de modificar sus circunstancias de acuerdo con una concepción compartida por sus miembros de los valores humanos. Refuerza y mantiene el sentido de comunidad, como medio para conseguir el "bien común", en vez de promover el bien exclusivamente individual (p. 95).

Cuando se desarrolla una investigación-acción no se tiene claridad en muchos aspectos conceptuales y formales. Una creencia común es que a quien se le aplica (estudiantes, comunidades, etc.) 
son los que van a transformarse y la situación problemática va a ser resuelta o mejorar sustancialmente, pero un aspecto importante, y crucial, es que quienes aplican la investigación-acción también son transformados porque su propio accionar y las reflexiones sobre ese accionar, los conducen a un entendimiento más profundo del objeto de estudio y de los sujetos de la investigación.

A medida que se desarrolla la investigación y se reflexiona sobre ella, emergen necesidades, problemas, circunstancias no previstos, propias del hacer investigativo y de la naturaleza humana, en ocasiones el método es insuficiente y debemos aplicar soluciones creativas en el marco de la rigurosidad científica.

Las maestras participantes paulatinamente descubrieron, y se descubrieron, como quien le quita una cubierta a algo, que las prácticas pedagógicas anteriores no eran coherentes con los propósitos que tenían. Fue un proceso de concienciación producido en la interacción con las nuevas estrategias y los resultados que mostraban los niños. En un principio las docentes no comprendían suficientemente lo que hacían en el aula antes y después de la introducción de las nuevas estrategias. La comprensión emergió paralela al avance que mostraban los niños. La maduración la explica Vigotsky (1979) con su teoría de la Zona de Desarrollo Próximo.

En la medida que los niños comprendían mejor los textos, daban respuestas coherentes y a veces sorprendentes para las maestras, ellas se convencían de que lo que ahora hacían en el aula era correcto y que lo que hacían antes no era coherente con su intención de mejorar la comprensión lectora de sus estudiantes. De nada hubiera servido darles clases de "comprensión lectora" a las maestras porque eso era repetir el modelo conductista, fue necesario confrontarlas con sus prácticas pedagógicas, con una nueva práctica pedagógica, y no con una teoría pedagógica.

\section{Análisis del discurso}

El análisis del discurso es el tercer método, íntimamente ligado a los anteriores. A través del relato de los docentes rastreé las marcas que me indicaron qué estructura conceptual tenían sobre la lectura, tal 
como expresa Van Dijk (2010, p. 174) en cuanto al análisis del discurso, la psicología cognitiva nos ha enseñado que el procesamiento de textos o procesamiento del discurso "no es solamente procesamiento del lenguaje, sino también procesamiento de conocimiento" porque para producir y comprender secuencias coherentes de oraciones, debemos crear modelos mentales de los referentes y para ello, necesitamos activar, aplicar y especificar el conocimiento general del mundo. Los modos de pensar son traducidos y representados en nuestros discursos, cotidianos, científicos, formales o informales. Por ello Lotman (1999) nos dice que "Nos hallamos inmersos en el espacio de la lengua. Ni en las abstracciones convencionales más elementales podemos desvincularnos de este espacio que nos envuelve, pero del que somos parte, y al mismo tiempo es parte nuestra" (p. 159).

Por otro lado, no por casualidad, he afirmado desde el principio que la lectura es tanto un problema agudo como crónico. Es agudo porque atraviesa profundamente todo el sistema educativo. Pero es su carácter crónico el que le ha dado ese carácter agudo. Es la rueda del círculo vicioso generacional, un bucle retroactivo; cada vez que pasa ahonda la zanja y desmejora la calidad educativa. Es su carácter fractal que se reproduce desde la escuela hasta la universidad y los estudios de cuarto y quinto nivel. Klingler y Vadillo (2003) comentan:

...la pregunta clave es: ¿Cuál es la mejor definición de lectura?, pues dependiendo de la que el maestro tenga, pondrá más o menos énfasis en su elemento de decodificación (la posibilidad de descifrar las letras para agruparlas en palabras) o de comprensión (que trata sobre el contenido de lo que se lee). Los lectores ineficientes definen a la lectura por su elemento de decodificación de símbolos; mientras los lectores eficientes se centran en la comprensión (p. 105).

Al develar esta realidad llegamos a la raíz del problema, pero luego debimos explorar cuán profunda es la raíz, cuál es marco, su contexto. La escuela, el liceo y la misma universidad se han rutinizado, la forma en que se reproduce la práctica de la experiencia docente se agota. Recordemos que la escuela es producto de la modernidad y nace tal como la conocemos bajo los preceptos del conductismo. 
La rutina, fábrica reproductora de lo mismo incasablemente, fue su principal objetivo; estandarizar la producción de mano de obra barata para que fuera productiva y acorde con los nuevos tiempos. La escuela actual responde a esa concepción del mundo. La escuela está en crisis, nada nuevo, sobre todo si reconocemos como cierta la sensación de la pérdida de la calidad. La escuela está en crisis porque la sociedad está en crisis, y no al contrario, solo que una escuela decadente agudiza el desequilibrio, la inestabilidad.

La crisis actual es -en realidad- la suma de crisis recurrentes que ponen en cuestión la presencia de la escuela y su particular forma de organización de la educación, porque al mismo tiempo que se profundizan las demandas de la sociedad, se constatan las imposibilidades para poder responder adecuadamente con las pautas proclamadas y vigentes desde la modernidad. Pareciera que la escuela, demasiado apegada a los moldes modernos, no ha sabido o no ha podido resolver el antagonismo entre el quiebre de la modernidad y la supervivencia de algunas de sus estructuras. La misma sociedad que protesta y denuncia su incapacidad, mantiene tácitamente su vigencia y reclama su intervención al constatar las dificultades y limitaciones para remediar las dificultades de los nuevos tiempos (Noro, 2010).

Bauman (2009), divide a la modernidad en pesada y líquida. La primera es la de los átomos fuertemente enlazados, característica propia de los sólidos, tiene gran estabilidad pero no se pueden adaptar a ningún recipiente, contrario a la segunda, líquida, sinónimo de fluidez y adaptabilidad. Nuestra educación, nuestra escuela, nace en la primera modernidad y a pesar del evidente agotamiento de ésta, la escuela pareciera continuar incólume, intocada por el tiempo que llega en oleadas suaves o en tsunamis. Mientras la postmodernidad, modernidad líquida, licuefacciona lo que toca, la escuela parece mirarse el ombligo y encerrarse como un quelonio.

El análisis del discurso nos ofrece la posibilidad de desentrañar la complejidad del mundo donde vivimos:

Como miembros de grupos socioculturales, los usuarios de las lenguas forman parte de la compleja red de relaciones de poder y de solidaridad, de dominación y de resistencia, 
que configuran las estructuras sociales, siempre en tensión entre la igualdad y la desigualdad, la identidad y la diferencia. Las identidades sociales de las personas - complejas, variadas e incluso contradictorias- se construyen, se mantienen y se cambian a través de los usos discursivos. Porque es en ellos donde se activan y se materializan esas caras que se eligen para cada ocasión. (Calsamiglia \& Tusón, 1999, p. 16)

¿El docente vive en la modernidad o en la postmodernidad? ¿Con qué modelo mental conforma su praxis pedagógica? El análisis del discurso nos permitió estudiar y develar las estructuras cognitivas profundas, los modos de pensar, las concepciones, los mundo-devida, las representaciones sociales con las cuales se organizan y estructuran su vida en la escuela.

Como ya se explicó, las docentes involucradas en la investigación tenían prácticas pedagógicas conductistas antes de la investigación. A continuación, presento algunas evidencias de su transformación expresadas en sus Trabajos de Grado y las categorías que emergieron al realizar los análisis correspondientes:

\begin{tabular}{|c|c|l|}
\hline Categoría & Docente & \multicolumn{1}{|c|}{ Evidencias de la validación } \\
\hline Cognitiva & RM & $\begin{array}{l}\text {. } \\
\text { haber sido diseñadas y aplicadas las diferentes } \\
\text { experiencias y estrategias de aprendizaje para } \\
\text { el logro de la comprensión de la lectura, los } \\
\text { estudiantes desarrollaron el pensamiento } \\
\text { inferencial, esto fue sustancial para el logro de } \\
\text { la lectura comprensiva. }\end{array}$ \\
\hline Cognitiva & $\begin{array}{l}\text { Cabe resaltar la variación positiva en la calidad } \\
\text { de la respuesta, observando mayor cantidad } \\
\text { de respuestas acertadas y menor cantidad } \\
\text { de desaciertos con respecto a los resultados } \\
\text { obtenidos al inicio, evidenciando el incremento } \\
\text { en cuanto a la producción de inferencias y la } \\
\text { clasificación eficaz y eficiente de los tipos de } \\
\text { respuestas. }\end{array}$ \\
\hline
\end{tabular}




\begin{tabular}{|c|c|c|}
\hline Categoría & Docente & Evidencias de la validación \\
\hline Cognitivo & PK & $\begin{array}{l}\text {...y el proceso de metacognición les ayudó a } \\
\text { reconocer y clasificar el nivel de las preguntas } \\
\text { y "a pensar más en las inferenciales" como } \\
\text { expresó un estudiante, que al principio se } \\
\text { les hacía difícil, pero la práctica constante } \\
\text { le permitió ejercitar y controlar su proceso } \\
\text { intelectual y la evaluación de los resultados, } \\
\text { tomando conciencia de cómo aprenden. }\end{array}$ \\
\hline Cognitivo & QA & $\begin{array}{l}\text {...los estudiantes pudieron desarrollar la } \\
\text { habilidad de interpretar y apropiarse de los } \\
\text { hechos que ocurrían en las lecturas y también } \\
\text { de relacionarlos con lo sucedido en su vida } \\
\text { diaria, todo esto se logró en el momento en } \\
\text { que la investigadora cumplió con su rol de } \\
\text { adulto significativo y consiguió despertar } \\
\text { en los educandos la motivación a través de } \\
\text { los estímulos positivos que le facilitó a los } \\
\text { mismos ser capaces de reproducir en forma } \\
\text { colectiva los aprendizajes obtenidos mediante } \\
\text { la socialización de saberes y experiencias } \\
\text { significativas. }\end{array}$ \\
\hline Social & PK & $\begin{array}{l}\text { De igual forma se generó un clima socio- } \\
\text { afectivo de confianza, respeto y libertad } \\
\text { de expresión, para que los estudiantes } \\
\text { pudieran sentirse en un ambiente cómodo } \\
\text { para responder sin cohibirse, sin miedo, } \\
\text { sin nada que lo perturbará o los afectara } \\
\text { psicológica o emocionalmente, y también se } \\
\text { sentían a gusto con las lecturas y cuando a } \\
\text { empezaron a trabajar por equipos, lo cual fue } \\
\text { muy efectivo porque los niños lo disfrutaron } \\
\text { mucho y mejoraron notablemente la calidad } \\
\text { de respuestas a través de la socialización como } \\
\text { dice Vigotsky, incluso hasta superaron las } \\
\text { expectativas de la investigadora y docente de } \\
\text { aula, integrándose hasta los niños más tímidos, } \\
\text { siendo una experiencia enriquecedora para } \\
\text { todos los participantes del proceso. }\end{array}$ \\
\hline
\end{tabular}




\begin{tabular}{|c|c|c|}
\hline Categoría & Docente & Evidencias de la validación \\
\hline Afectivo & RM & $\begin{array}{l}\text { Mi experiencia como investigadora en el aula } \\
\text { fue sorprendente y satisfactoria. Sorprendente } \\
\text { porque no sabía todo lo que los estudiantes } \\
\text { tienen, que uno como docente no ve cuando } \\
\text { tiene una posición de imponer lo que dice } \\
\text { el programa y de exigir lo que el programa } \\
\text { establece. Satisfactoria porque cuando uno } \\
\text { cambia de paradigma, de pensamiento pone a } \\
\text { un lado las exigencias y toma en cuenta que el } \\
\text { estudiante es un ser humano, que se enferma, } \\
\text { que se pone nervioso en las evaluaciones, que } \\
\text { hay calor en el aula ya que no hay ventiladores y } \\
\text { esto trae como consecuencia bajo rendimiento } \\
\text { académico. Que tiene familia y problemas } \\
\text { familiares, no es que el docente se inmiscuya } \\
\text { en los problemas del estudiante, pero a veces } \\
\text { es mejor conversar y darle ánimos para seguir, } \\
\text { que pegarle tres gritos: "ihaz la tarea!", como } \\
\text { docente darle la oportunidad otro día. }\end{array}$ \\
\hline Afectivo & FW & $\begin{array}{l}\text { Trabajaban con regocijo cada actividad, ya en } \\
\text { ese momento el plan de acción funcionaba con } \\
\text { bastante acierto, me encantó tanto como a la } \\
\text { mayoría de ellos. }\end{array}$ \\
\hline Afectivo & FW & $\begin{array}{l}\text { El ambiente cambió radicalmente. Los } \\
\text { niños pasaron de aquel momento inicial de } \\
\text { aburrimiento y apatía a preguntar con mucha } \\
\text { frecuente y entusiasmo "Maestra, ¿hoy vamos } \\
\text { a leer cuentos?" o cuando me veían que yo } \\
\text { cargaba libros de cuentos demostraban su } \\
\text { alegría. }\end{array}$ \\
\hline
\end{tabular}

El hallazgo inicial no indicó que nuestras maestras, grosso modo, continúan concibiendo la lectura. Desde el paradigma silábico: leer es decodificar, descifrar sonidos. Se enseña a leer con silabarios, en ellos subyace una concepción de la lectura; no hay comprensión, no hay disfrute.

Sin embargo, el maestro no posee una "teoría" consciente, articulada y coherente, lo cual le produce disonancias cognitivas. 
Percibe, intuye y/o sabe que no cumple con su papel cabalmente en cuanto a la lectura, ellos mismo afirman: "a los niños no les gusta leer, no comprenden lo que leen, para ellos la lectura es aburrida”. Separan enseñar a leer del acto de leer.

En general, el método utilizado para alfabetizar en Venezuela es el implícito en los silabarios, es decir, el método sintético que comienza por las letras, pasa a las sílabas y llega a las palabras: va de lo particular a lo general. Y, por supuesto, los textos de lectura utilizados por el maestro son los incluidos en los silabarios, es decir, palabras e imágenes ajenas al contexto lingüístico de los aprendices.

Los silabarios modernos -entiéndase de la modernidadutilizan el método centrado en lo fonético y plantean que primero deben ser adquiridos los sonidos de las letras para formar las sílabas, con éstas se forman las palabras y de las palabras se pasa a las frases u oraciones sin importar la comprensión de las mismas. Supone que los niños "leen" cuando son capaces de pronunciar en voz alta las sílabas de las palabras. La comprensión se trabajará más adelante, pero la comprensión de textos nunca llega. Los actos de "escribir" son fundamentalmente la copia y el dictado.

Sin embargo, luego de una experiencia, en el caso particular de las maestras involucradas de la investigación, y sobre todo de una vivencia, de contacto con la investigación-acción en el aula, el cambio ocurrido en sus estudiantes las transformó a ellas, fueron los hechos concretos los que las convencieron de que lo que hacían ahora era lo correcto, no solo por los resultados fehacientes de sus alumnos en cuanto a una mejoría notable en la comprensión de textos, sino también, por su cambio de actitud de hacia la lectura. Sin duda, las teorías y los autores sobre la lectura ahora son mejor comprendidos, dejaron de ser abstracciones vacías para ellas y pasaron a ser un soporte de su hacer pedagógico.

Estamos en presencia de un círculo virtuoso, la práctica refuerza la teoría y la teoría refuerza la práctica. Esta relación dialéctica, diálogo virtuoso, constituye un aspecto para futuras investigaciones en el aula. El círculo virtuoso es el bucle retroactivo positivo, porque la causa actúa sobre el efecto y el efecto sobre la causa, el resultado 
es amplificador, es decir, cada vez más intenso (Morin, 1999, p. 99). Con ello se rompe el círculo vicioso del conductismo que se refuerza a sí mismo y empobrece cada vez más la educación.

\section{Conclusiones}

He evidenciado que desde los postgrados donde se práctica el paradigma crítico reflexivo pueden surgir importantes elementos de transformación en las escuelas. Este efecto puede ser multiplicador.

El libro, desde sus orígenes, ha sido la forma por excelencia de transmisión de la cultura, cualquier forma que tome en el presente y en el futuro necesitará de la interpretación del ser humano. La escuela es la institución que garantiza la permanencia de esa cultura y, paradójicamente, la evolución del pensamiento humano que la hará cambiar. Si la única constante es el cambio, las instituciones educativas deben formar para y en el cambio, para y en el cambio crítico. Para llegar a los niveles de comprensión comprehensiva, todo el sistema educativo deberá estar dirigido al desarrollo de la criticidad crítica, de la reflexión reflexiva de un humano humanizador.

Nicolescu (1999) nos alerta:

A educação atual privilegia o intelecto, em detrimento da sensibilidade e do corpo. Isso foi certamente necessário em determinada época para permitir a explosão do conhecimento. Mas se esse privilégio continuar nos arrastará para a lógica louca da eficiência pela eficiência, que só pode desembocar em nossa autodestruição.

La educación actual privilegia el intelecto en detrimento de su sensibilidad y de su cuerpo, que fue ciertamente necesario en determinada época para permitir la explosión del conocimiento. Sin embargo, si ese privilegio sigue, nos va a arrastrar hacia la lógica loca de la eficiencia por la eficiencia, que sólo puede desembocar en nuestra autodestrucción. ${ }^{2}$

2Traducción libre. 
No somos sólo intelecto, también somos seres sensibles y sociales, esta tríada debe estar presente en nuestra educación ¿Podemos vivir sin amor? ¿Hubiera sobrevivido la humanidad si fuéramos ermitaños? La comprensión del ser humano pasa por la comprensión de la otredad, por la sensibilidad de ponerse en lugar del otro.

Dificulto que la transformación del docente se dé en solitario, es necesario el acompañamiento y la reflexión en colectivo, círculos de estudio, compartir experiencias para que se incorpore de forma natural a su modo de pensar y actuar; debe ser parte de la cultura de la escuela, es una manera de romper con el bucle retroactivo en tanto círculo vicioso, la tradición debe ser vencida por/con el pensamiento crítico.

La formación de docentes investigadores cualitativos es central para la ruptura del pensamiento de la modernidad. El paradigma crítico reflexivo no solo exige la formación teórica y empírica, sino también una gran dosis de creatividad porque el pensamiento moderno encuadra lo que toca, en cambio la "modernidad líquida", licuefacciona. El peligro de canonizar las investigaciones cualitativas siempre estará latente, es una tensión constante entre un modo de pensar y otro. El surgimiento de métodos alternativos de investigación siempre será el triunfo de la creatividad humana.

\section{Referencias}

Aristóteles. Metafísica. (1994). Libro IV. Editorial Gredos: Madrid.

Barboza, J. (2009). Estrategias interactivas grupales para consolidar la comprensión lectora. Trabajo especial de grado para optar al título de Magister Scientiarum en Docencia para la Educación Superior. Universidad Nacional Experimental Rafael María Baralt.

Bauman, Z. (2009). Modernidad líquida. 11 reimp. Buenos Aires, Argentina: Fondo de Cultura Económica.

Calsamiglia, H., \& Tusón, A. (1999). Las cosas del decir. Manual de análisis del discurso. Barcelona, España: Editorial Ariel, S.A. 
Carr, W., \& Kemmis, S. (1988). Teoría Crítica de la enseñanza. La investigación-acción en la formación del profesorado. Barcelona, España: Ed. Martínez Roca.

Coulon, A. (1988). La etnometodología. Madrid. España: Ediciones Cátedra.

Elliott, J. (1994). La investigación-acción en educción. 2da. ed. Madrid, España: Morata.

Ferreiro, E., \& Teberosky, A. (1991). Los sistemas de escritura en el desarrollo del niño. 12da. ed. México: Siglo XXI.

Garfinkel, H. (2006). Estudios en Etnometodología. Barcelona, España: Anthropos Editorial.

Klingler, C., \& Vadillo, G. (2003). Psicología Cognitiva. Estrategias en la práctica docente. México.

Lotman, Yuri M. (1999). Cultura y Explosión. Lo previsible y lo imprevisible en los procesos de cambio social. Barcelona (España): Editorial Gedisa.

Lyotard, J. (1991). La condición postmoderna. Informe del saber. Buenos Aires, Argentina: Editorial R.E.I. Argentina S.A. Versión digital.

Morin, E. (1999). La Cabeza Bien Puesta: Repensar la reforma, reformar el pensamiento. Buenos Aires, Argentina: Ediciones Nueva Visión.

Nicolescu, B. (1999). Um novo tipo de conhecimento transdisciplinaridade. En: Educação e Transdisciplinaridade. $1^{\circ}$ Encontro Catalisador do CETRANS - Escola do Futuro - USP, Itatiba, São Paulo - Brasil: abril de 1999. http://unesdoc.unesco. org/images/0012/001275/127511por.pdf [Consulta: 14 may 2016]

Noro, J. (2010). Origen, glorificación y crisis de la escuela moderna: De la escuela sagrada a la escuela profanada. Investigación y Postgrado [online]. 2010, vol. 25, n. 2-3 pp. 109-114. [Información en línea]: <http://www.scielo.org.ve/scielo.php?script=sci_arttext\&pid=S1316-00872010000200010\&lng=es\&nrm=iso>. ISSN 1316-0087. [Consulta: 07 ago 2014]. 
Sánchez, M. de (1996). El Pensamiento Lógico Crítico. Editorial de la Universidad Santiago de Compostela. España.

Sánchez, M. de (1997). Aprender a Pensar. Nivel I. Planifica y Decide. Centro CDIP-CIED. Venezuela.

Sánchez, M. de (2000). Aprender a Pensar. Organización del Pensamiento. México: Editorial Trillas.

Taylor S., \& Bogdan R. (1992) Introducción a los métodos cualitativos de investigación. México: Paidós.

Van Dijk, T. A. (2010). Discurso, conocimiento, poder y política. Hacia un análisis crítico epistémico del discurso. Revista de investigación lingüística, 13, 167-215.

Vigotsky, L. S. (1979). Zona de desarrollo próximo: una nueva aproximación. El desarrollo de los procesos psicológicos superiores. Barcelona, Grijalbo. 